Vieira JV; Silva GO; Charchar JM; Fonseca MEN; Silva JBC; Nascimento WM; Boiteux LS; Pinheiro JB; Reis A; Resende FV; Carvalho ADF. 2012. BRS Planalto: cultivar de cenoura de polinização aberta para cultivo de verão. Horticultura Brasileira 30: 359-363.

\title{
BRS Planalto: cultivar de cenoura de polinização aberta para cultivo de verão
}

\author{
Jairo V Vieira; Giovani O da Silva; João M Charchar; Maria Esther de N Fonseca; João BC Silva; War- \\ ley M Nascimento; Leonardo S Boiteux; Jadir B Pinheiro; Ailton Reis; Francisco V Resende; Agnaldo DF \\ de Carvalho
}

Embrapa Hortaliças, C. Postal 218, 70351-970 Brasília-DF; jairo@cnph.embrapa.br

\begin{abstract}
RESUMO
O grupo varietal Brasília apresenta ampla adaptação para cultivo em regiões/épocas de clima mais quente e tolerância às principais doenças que afetam o cultivo da cenoura em regiões tropicais e subtropicais ("queima-das-folhas" e as galhas radiculares causadas por nematóides do gênero Meloidogyne). No entanto, algumas cultivares desse segmento apresentam elevada incidência de defeitos genéticos que afetam a qualidade visual, sensorial e nutricional das raízes. A Embrapa Hortaliças desenvolveu a cultivar BRS Planalto, visando minimizar parte destas limitações. 'BRS Planalto' é uma variedade de polinização aberta que foi desenvolvida a partir da cultivar de cenoura 'Brasília'. Foram realizados 18 ciclos de seleção recorrente, com base no desempenho de progênies de meios-irmãos. Em cada ciclo de seleção foram feitas avaliações para caracteres fenotípicos, separadamente em cada família de meios-irmãos, em duas repetições com parcelas de $1 \mathrm{~m}^{2}$ (aproximadamente 100 raízes por parcela). 'BRS Planalto' apresenta maior uniformidade do xilema e floema e uma coloração de raiz laranja mais escura que 'Brasília', devido a uma maior acumulação dos pigmentos $\alpha$-caroteno e $\beta$-caroteno (precursores da vitamina A). Além disso, 'BRS Planalto' apresenta maior tolerância ao florescimento precoce no verão associada com baixas incidências de raízes com ombro verde, ombro roxo e halo branco. As raízes de 'BRS Planalto' possuem melhor aparência e formato mais padronizado. Além destas características, essa cultivar mostrou bom potencial produtivo, tanto em cultivo convencional quanto orgânico. Desta forma, 'BRS Planalto' poderá ocupar uma posição estratégica dentro da cadeia produtiva de cenoura no Brasil, representando uma opção com melhor qualidade visual e nutricional de raízes quando comparada com outras cultivares do grupo Brasília.
\end{abstract}

Palavras-chave: Daucus carota, carotenóides, Alternaria dauci, Meloidogyne spp., produtividade, melhoramento.

\section{ABSTRACT}

BRS Planalto: An open pollinated carrot cultivar adapted for cultivation under summer season conditions

The variety group 'Brasília' is still largely cultivated during the summer season in Brazil. These open pollinated cultivars are adapted to warm climates/regions and they present field resistance to the leaf blight disease complex and to root-knot nematodes (genus Meloidogyne), which are the two major biotic problems in tropical and subtropical regions. However, some cultivars of the 'Brasília' group have important genetic disorders with negative impacts on the visual, sensorial, and nutritional quality of the roots. 'BRS Planalto' is a new open pollinated cultivar released by the Embrapa Vegetable Crops breeding program, aiming to minimize much of these problems. 'BRS Planalto' was developed after 18 cycles of recurrent selection based upon the performance of half-sib progenies using the cultivar Brasília as the basic germplasm. Evaluations were carried out in each selection cycle for a set of phenotypic traits using two replications (1 $\mathrm{m}^{2}$ plots) with about 100 roots per plot of each half-sib family. 'BRS Planalto' has a darker orange root color when compared to 'Brasília' due to the higher accumulation of the carotenoid pigments $\alpha$-carotene and $\beta$-carotene (vitamin A precursors). In addition, 'BRS Planalto' displays uniform xylem and phloem color and low incidence of precocious bolting during the warm season. 'BRS Planalto' has lower green and purple root shoulder incidences as well as lower frequency of white halo in the root tissue when compared to 'Brasília'. 'BRS Planalto' has also a more uniform root pattern (shape and size) when compared to other cultivars of the 'Brasília' group. 'BRS Planalto' is adapted to both conventional and organic crop systems and presents a very high yield potential. Therefore, 'BRS Planalto' might occupy a strategic role in the Brazilian carrot agribusiness chain due to its improved visual and nutritional root qualities when compared to other cultivars of the 'Brasília' variety group.

Keywords: Daucus carota, carotenoids, Alternaria dauci, Meloidogyne spp., yield, breeding.

(Recebido para publicação em 26 de agosto de 2011; aceito em 26 de abril de 2012)

(Received on August 26, 2011; accepted on April 26, 2012)

$\mathrm{E}_{\mathrm{s}}^{\mathrm{n}}$ mbora tenha sido observada uma grande expansão do cultivo de híbridos de cenoura (Daucus carota) no Brasil, as cultivares de polinização aberta do grupo varietal Brasília ainda apresentam grande importância, ocupando uma significativa fração do mercado para cultivo de verão. Cultivares desse grupo varietal apresentam adaptação para cultivo em regiões ou épocas com temperaturas elevadas e também tolerância/resistência à "queima-das-folhas" e aos nematoides formadores de galhas radiculares (Meloidogyne spp.), que são as duas principais doenças que 
afetam o cultivo da cenoura em regiões tropicais e subtropicais (Boiteux et al., 1993; Vieira et al., 2003). Além disso, as cultivares de polinização aberta de cenoura apresentam sementes de menor valor unitário quando comparadas com os híbridos $\mathrm{F}_{1}$, reduzindo os custos fixos de produção para os agricultores.

No entanto, algumas cultivares do grupo varietal Brasília apresentam, em associação com estas características positivas, uma elevada incidência de raízes com defeitos de origem genética que afetam negativamente a qualidade visual, sensorial e nutricional. Entre os defeitos a serem minimizados encontram-se a presença de ombro verde/roxo, halo branco e reduzido teor de carotenóides, principalmente no xilema. Para tentar solucionar parte destas limitações, a Embrapa Hortaliças desenvolveu a cultivar de polinização aberta BRS Planalto. Devido às suas características, a 'BRS Planalto' poderá ocupar uma posição estratégica na cadeia produtiva de cenoura, representando uma opção com melhor qualidade visual e nutricional de raízes quando comparada com outras cultivares do grupo varietal Brasília.

\section{Origem}

A cultivar BRS Planalto foi desenvolvida pelo programa de melhoramento genético da Embrapa Hortaliças a partir da cultivar de cenoura Brasília. Foram realizados 18 ciclos de seleção recorrente, com base no desempenho de progênies de meios-irmãos e via seleção por "níveis independentes de eliminação". Em cada ciclo de seleção foram avaliadas cada família de meios-irmãos separadamente em duas repetições e parcelas de $1 \mathrm{~m}^{2}$ (aproximadamente 100 raízes por parcela). Para queima-das-folhas, foram atribuídas notas de 1 a 5 , sendo 1 (sem sintomas) e 5 (parcela completamente comprometida pela doença). Foram eliminadas todas as famílias que apresentaram notas maiores do que as testemunhas ('Nantes' e 'Brasília') e também aquelas que apresentaram mais de duas plantas florescidas precocemente por parcela.

Após a colheita das famílias remanescentes, foram realizadas avaliações visuais, a campo, para maior rendimento de raízes com tamanho comercial e características de raiz como comprimento (aproximadamente 16 a $20 \mathrm{~cm}$ ), diâmetro da raiz (16 a $20 \mathrm{~cm}$ ), formato cilíndrico, ponta arredondada, baixa incidência de ombro verde e/ou roxo e pequena rugosidade da raiz. As famílias selecionadas foram levadas à câmara fria onde permaneceram a $4^{\circ} \mathrm{C}$ por um período de aproximadamente 50 dias. Após o período de vernalização as raízes foram novamente selecionadas para os seguintes caracteres externos: comprimento, diâmetro, formato cilíndrico, tipo de ponta, incidência de ombro verde e/ou roxo e rugosidade, e para os caracteres internos: coloração alaranjada intensa do xilema e floema da raiz, uniformidade de coloração entre xilema e floema, menor rugosidade de casca e ausência de halo branco. Após este processo, as raízes remanescentes foram plantadas a campo iniciando um novo ciclo de seleção recorrente.

\section{Descrição}

A cultivar BRS Planalto apresenta coloração de raiz laranja escura quando comparada com 'Brasília', resultado do maior acúmulo dos pigmentos $\alpha$-caroteno e $\beta$-caroteno (precursores da vitamina A), com $72 \mu \mathrm{g} \mathrm{g}^{-1}$ de carotenóides totais $(78 \%$ superior aos níveis observados em ensaios comparativos com a cultivar Brasília). Além disso, a cultivar BRS Planalto manifesta baixa incidência de florescimento precoce no verão. 'BRS Planalto' apresenta boa aparência interna (coloração alaranjada intensa e uniforme para os tecidos do xilema e floema e reduzida presença de halo branco) e externa (coloração alaranjada intensa, com pouco ombro verde e roxo, lisas, com formato cilíndrico e ponta arredondada) das raízes. 'BRS Planalto' mostrou ainda elevado potencial produtivo, tanto em cultivo convencional quanto orgânico, além de bom nível de resistência à queima-das-folhas (superior à da cultivar Brasília). 'BRS Planalto' apresentou alta resistência aos nematóides formadores de galhas nas raízes, (Meloidogyne ssp.) com nível semelhante ao encontrado nas cultivares do grupo Brasília, apesar de não ter sido realizada seleção diretamente para este fim. Essa cultivar apresenta ainda formato padronizado das raízes, comprimento de raiz variando de 16 a $20 \mathrm{~cm}$ e diâmetro médio de 2,5 cm. Algumas dessas características foram avaliadas em duas safras agrícolas (2007/2008 e 2008/2009), onde 'BRS Planalto' se destacou positivamente em avaliações de cultivares e populações avançadas do programa de melhoramento de cenoura da Embrapa. Estas avaliações foram realizadas, em 100 raízes de cada uma das cultivares e populações (Brasília, Alvorada, Esplanada, BRS Planalto, 0912545, 0912552 e 0912520), em Brasília-DF. Os seguintes caracteres foram avaliados: Diâmetro de raiz: medido no terço superior da raiz com a utilização de paquímetro. Formato longitudinal da raiz, com escala de notas onde, $1=$ circular, $2=$ ovalada, $3=$ oval triangular, 4= oblonga; cor externa da raiz: notas onde, $3=$ clara, $5=$ média, $7=$ escura. Incidência de ombro verde: notas onde, $1=$ ausente, $2=$ pouco presente, $3=$ medianamente presente, $4=$ presença de média a alta; $5=$ presença muito grande. Rugosidade da raiz: notas $1=$ ausente, $2=$ pouco presente, $3=$ medianamente presente, $4=$ média a alta, $5=$ muito intensa) e Tipo de ponta de raiz: escala de notas onde $1=$ arredondada, $2=$ levemente afilada, $3=$ afilada.

Pode-se verificar que 'BRS Planalto' produziu raízes com aproximadamente $16 \mathrm{~cm}$ de comprimento e $2,3 \mathrm{~cm}$ de diâmetro, e níveis de produtividade de 50 a 60 toneladas de raízes comerciais por hectare. As raízes apresentam-se grossas e com películas lisas, com coloração externa alaranjada intensa e coloração interna alaranjada e de intensidade uniforme entre o xilema e o floema. 'BRS Planalto' apresentou baixa incidência de ombro verde e roxo e ausência de halo branco, com formato cilíndrico, coloração externa escura, reduzida quantidade de ombro verde (Tabela 1).

\section{Rendimento de raízes comerciais}

O rendimento de raiz foi avaliado em dois anos agrícolas (2007/2008 e 2008/2009), em cinco locais: São Gotardo (MG); Irecê (BA) e Gama (DF), em cultivo convencional, e Gama (DF) e PAD-DF (Programa de Assentamento Dirigido) em cultivo orgânico. O deli- 
Tabela 1. Avaliação de 100 raízes de sete cultivares/populações de cenoura para caracteres fenotípicos avaliados nos anos agrícolas de 2007/2008 e 2008/2009 (evaluation of 100 roots of seven carrot cultivar/breeding populations for phenotypic traits measured in two growing seasons 2007/2008 and 2008/2009). Brasilia, Embrapa Hortaliças, 2009.

\begin{tabular}{|c|c|c|c|c|c|}
\hline Cultivar/População & $\begin{array}{l}\text { Diâmetro de } \\
\text { raiz }(\mathbf{m m})\end{array}$ & $\begin{array}{c}\text { Formato } \\
\text { longitudinal }^{1}\end{array}$ & $\begin{array}{c}\text { Cor } \\
\text { externa }^{2}\end{array}$ & $\begin{array}{l}\text { Ombro } \\
\text { verde }^{3}\end{array}$ & $\begin{array}{l}\text { Rugosidade } \\
\text { da raiz }\end{array}$ \\
\hline 0912539 & 21,54 & 3,65 & 4,78 & 1,92 & 3,38 \\
\hline BRS Planalto & 23,25 & 3,78 & 5,02 & 2,04 & 3,38 \\
\hline Alvorada & 11,75 & 3,43 & 4,98 & 1,86 & 4,56 \\
\hline 0912520 & 17,90 & 3,68 & 4,92 & 2,26 & 3,63 \\
\hline Esplanada & 18,07 & 3,18 & 5,04 & 2,50 & 3,58 \\
\hline Brasília & 18,08 & 3,73 & 4,95 & 2,74 & 3,60 \\
\hline 0912534 & 20,71 & 3,66 & 5,02 & 2,02 & 3,74 \\
\hline
\end{tabular}

${ }^{1}$ notas $1=$ circular, $2=$ ovalada, $3=$ oval triangular, $4=$ oblonga; ${ }^{2}$ notas $3=$ clara, $5=$ média, $7=$ escura; ${ }^{3}$ notas de 1 (ausente) a 5 (muito grande); ${ }^{4}$ notas de 1 (ausente) a 5 (muito forte). ( ${ }^{1}$ grades $1=$ circular, $2=$ oval, $3=$ oval triangular, $4=$ oblong; ${ }^{2}$ grades $3=$ light, $5=$ medium, $7=$ dark; ${ }^{3}$ grades from 1 (absent) to 5 (very strong); ${ }^{4}$ grades from 1 (absent) to 5 (very strong)).

neamento experimental utilizado foi de blocos ao acaso com três repetições. Foram avaliadas além de 'BRS Planalto', outras três populações elite (códigos 0912545, 0912532 e 0912520) e três cultivares ('BRS Esplanada', 'Brasília' $\mathrm{e}$ 'Alvorada", todas pertencentes ao grupo varietal Brasília). As parcelas constituíram-se de $1 \mathrm{~m}^{2}$, com espaçamento de 20 $\mathrm{cm}$ entre linhas e $5 \mathrm{~cm}$ entre plantas, com 100 plantas por parcela. Aos 100 dias após a semeadura foi determinada, em cada parcela, a massa fresca das raízes com padrão comercial (g), de acordo com aquele proposto pela Ceagesp (1999), sendo considerado como raiz não-comercial aquelas com diâmetro do terço médio superior inferior a 2 cm. O aplicativo computacional Genes
(Cruz, 1997) foi utilizado para realizar a análise de variância individual e conjunta, além do agrupamento de médias por Scott-Knott. A análise de variância conjunta em relação à massa fresca de raízes comerciais revelou que os efeitos de genótipos (G), anos (A) e locais de semeadura (L) apresentaram variações significativas a $1 \%$ de probabilidade pelo teste $\mathrm{F}$. O coeficiente de variação foi de $13,78 \%$ conferindo boa precisão ao experimento, já que o caráter massa de raiz é altamente influenciado pelo ambiente (Vieira et al., 2009). Também houve interação entre genótipos e ambientes, indicando que os genótipos avaliados apresentaram respostas diferenciadas quando submetidos aos diferentes locais de semeadura, ocor- rendo alteração no posicionamento dos genótipos ou mudanças na magnitude das diferenças entre populações e os locais de semeadura. Já a interação das populações com ano de cultivo não foi significativa, indicando comportamento semelhante das populações nos dois anos avaliados (dados não apresentados), sendo assim, as médias foram agrupadas na média dos dois anos (Tabela 2). Para Irecê (BA), onde não houve diferenças significativas, a cultivar BRS Planalto, juntamente com todas as populações avançadas (códigos 912545, 912532 e 912520) apresentaram suas médias estatisticamente superiores para todos os locais, indicando adaptação ampla ao cultivo. A cultivar BRS Planalto superou as cultivares BRS

Tabela 2. Médias para o caráter massa fresca de raízes com padrão comercial (gramas) de populações de cenoura avaliadas em dois anos agrícolas (2007/2008 e 2008/2009) (means for the character root mass with marketable standard (grams) of carrot germplasm evaluated in two growing seasons (2007/2008 and 2008/2009)). Brasilia, Embrapa Hortaliças, 2009.

\begin{tabular}{lcccccc}
\hline Cultivar/População & $\begin{array}{c}\text { São Gotardo } \\
\text { (MG) }\end{array}$ & PAD-DF & $\begin{array}{c}\text { Gama (DF) } \\
\text { orgânico }\end{array}$ & $\begin{array}{c}\text { Gama (DF) } \\
\text { convencional }\end{array}$ & Irecê (BA) & Médias \\
\hline 0912545 & $11.005,6 \mathrm{a}^{*}$ & $3.626,7 \mathrm{a}$ & $6.476,7 \mathrm{a}$ & $3.011,7 \mathrm{a}$ & $6.609,2 \mathrm{a}$ & $6.145,9$ \\
0912532 & $11.547,2 \mathrm{a}$ & $3.560,0 \mathrm{a}$ & $6.845,0 \mathrm{a}$ & $2.858,3 \mathrm{a}$ & $6.755,8 \mathrm{a}$ & $6.313,3$ \\
0912520 & $12.211,1 \mathrm{a}$ & $3.923,3 \mathrm{a}$ & $6.563,0 \mathrm{a}$ & $3.151,7 \mathrm{a}$ & $6.658,3 \mathrm{a}$ & $6.501,5$ \\
BRS Planalto & $11.646,7 \mathrm{a}$ & $3.601,7 \mathrm{a}$ & $6.158,3 \mathrm{a}$ & $3.076,7 \mathrm{a}$ & $7.232,5 \mathrm{a}$ & $6.343,2$ \\
Esplanada & $9.345,0 \mathrm{~b}$ & $3.026,7 \mathrm{a}$ & $5.251,7 \mathrm{~b}$ & $2.046,7 \mathrm{~b}$ & $6.220,8 \mathrm{a}$ & $5.178,2$ \\
Brasília & $11.234,5 \mathrm{a}$ & $2.070,0 \mathrm{~b}$ & $6.535,0 \mathrm{a}$ & $1.973,3 \mathrm{~b}$ & $7.607,5 \mathrm{a}$ & $5.884,1$ \\
Alvorada & $10.765,3 \mathrm{a}$ & $1.826,7 \mathrm{~b}$ & $4.935,0 \mathrm{~b}$ & $1.440,0 \mathrm{c}$ & $6.160,0 \mathrm{a}$ & $5.025,4$ \\
Médias & $11.107,9$ & $3.090,7$ & $6.109,2$ & $2.508,3$ & $6.749,2$ & $5.913,1$ \\
\hline CV (\%) & 6,30 & 12,30 & 10,41 & 12,14 & 9,12 & \\
\hline
\end{tabular}

*Médias seguidas de mesma letra na coluna não diferem pelo teste de agrupamento Scott-Knott a 5\% de probabilidade (means followed by same letters in the column do not differ statistically by Scott-Knott at 5\% of probability). 
Tabela 3. Médias de acessos de cenoura para as características carotenóides totais, $\beta$-caroteno, $\alpha$-caroteno, relação $\beta$-caroteno/ $\alpha$-caroteno, luteína e retinol equivalente (microgramas por grama) (means of carrot accessions for the traits total carotenoids, $\beta$-carotene, $\alpha$-carotene, ratio $\beta$-carotene/ $\alpha$-carotene ratio, lutein and retinol equivalent (micrograms per gram)). Brasilia, Embrapa Hortaliças, 2009.

\begin{tabular}{lcccccc}
\hline Cultivar/População & $\begin{array}{c}\text { Carotenóides } \\
\text { totais }\end{array}$ & B-caroteno & $\alpha$-caroteno & Relação $\beta / \alpha$ & Luteína & $\begin{array}{c}\text { Retinol } \\
\text { equivalente* }\end{array}$ \\
\hline População \#04 & $70,67 \mathrm{a} * *$ & $35,57 \mathrm{a}$ & $33,31 \mathrm{a}$ & 1,068 & $0,79 \mathrm{a}$ & $4,40 \mathrm{a}$ \\
População \#22 & $69,00 \mathrm{a}$ & $34,88 \mathrm{a}$ & $37,01 \mathrm{a}$ & 0,942 & $0,21 \mathrm{a}$ & $4,45 \mathrm{a}$ \\
Nantes & $54,33 \mathrm{a}$ & $29,95 \mathrm{a}$ & $21,13 \mathrm{a}$ & 1,417 & $1,86 \mathrm{~b}$ & $3,37 \mathrm{a}$ \\
BRS Planalto & $72,20 \mathrm{a}$ & $44,82 \mathrm{a}$ & $28,47 \mathrm{a}$ & 1,574 & $0,00 \mathrm{a}$ & $4,92 \mathrm{a}$ \\
BRS Esplanada & $138,00 \mathrm{~b}$ & $70,34 \mathrm{~b}$ & $62,32 \mathrm{~b}$ & 1,129 & $5,47 \mathrm{~d}$ & $8,46 \mathrm{~b}$ \\
Brasília & $56,00 \mathrm{a}$ & $31,24 \mathrm{a}$ & $18,23 \mathrm{a}$ & 1,714 & $4,46 \mathrm{c}$ & $3,36 \mathrm{a}$ \\
Alvorada & $70,33 \mathrm{a}$ & $34,56 \mathrm{a}$ & $28,27 \mathrm{a}$ & 1,222 & $4,14 \mathrm{c}$ & $4,05 \mathrm{a}$ \\
\hline CV (\%) & 16,59 & 15,64 & 22,63 & --- & 17,14 & 15,63 \\
\hline
\end{tabular}

*Retinol equivalente $=($ conteúdo de $\beta$-caroteno/12 + conteúdo de $\alpha$-caroteno/24), de acordo com Thurham (2007) (retinol equivalent $=$ (ß-carotene content/12 $+\alpha$-carotene content/24), according to Thurham (2007)).

**Médias seguidas de mesma letra na coluna não diferem pelo teste de agrupamento Scott-Knott a 5\% de probabilidade (means followed by same letters in the column do not differ statistically by Scott-Knott test at $5 \%$ of probability).

Esplanada e Alvorada em três locais e nos dois sistemas de cultivo no Distrito Federal (orgânico e convencional).

Teores de carotenóides totais, $\boldsymbol{\alpha}$-caroteno, $\boldsymbol{\beta}$-caroteno e luteína

A determinação do teor e dos tipos de carotenóides totais presentes nas raízes da cultivar BRS Planalto e de um grupo de cultivares (Nantes, BRS Esplanada, Brasília e Alvorada) e populações testemunhas (População \#04 e População \#22) foi realizada via extração com acetona e posterior análise por cromatografia líquida de alta eficiência (CLAE) em coluna C18 polimérica, utilizando-se uma mistura de acetonitrila:metanol:acetato de etila como fase móvel (Rodriguez-Amaya, 2001). O teor de carotenóides totais foi obtido a partir dos dados de massa e absorvância (450 nm) em éter de petróleo, utilizando-se a fórmula: [(Abs450nm) x $1.000,000 \times 100 /(2592 \times 100) / \operatorname{massa}(\mathrm{g})]$. A caracterização dos carotenóides da cultivar BRS Planalto foi feita através do espectro de absorção característico e tempo de retenção para cada pigmento. Os teores dos pigmentos luteína, $\beta$-caroteno e $\alpha$-caroteno foram estimados por padronização externa, via curvas de calibração construídas em cinco pontos com concentrações crescentes dos carotenóides (em três repetições). Os resultados indicaram um teor médio de $72,2 \mu \mathrm{g} \mathrm{g}^{-1}$ de carotenóides totais para a 'BRS Planalto'(Tabela 3). Observou-se um teor mais elevado de $\beta$-caroteno $\left(44,01 \mu \mathrm{g} \mathrm{g}^{-1}\right)$ em relação ao $\alpha$-caroteno $\left(28,13 \mu \mathrm{g} \mathrm{g}^{-1}\right)$, alcançando uma proporção de 1,574. Foram observados apenas traços do carotenóide luteína. O pigmento $\beta$-caroteno é a mais importante fonte vegetal de retinol, sendo que 12 $\mu \mathrm{g}$ de $\beta$-caroteno equivale a $1 \mu \mathrm{g}$ de retinol, enquanto são necessárias $24 \mu \mathrm{g}$ de $\alpha$-caroteno para a conversão em 1 $\mu \mathrm{g}$ de retinol (Thurnham, 2007). Adicionalmente, 'BRS Planalto' apresentou carotenóides totais equivalentes aos da cultivar Alvorada, porém com teores mais elevados do pigmento $\beta$-caroteno. Fenotipicamente a cultivar BRS Planalto apresenta coloração de raiz laranja escura, condicionada pela maior acumulação dos pigmentos $\alpha$-caroteno e $\beta$-caroteno (precursores da vitamina A) e coloração uniforme do xilema e floema. Nesses ensaios a 'BRS Planalto' apresentou teores de $\beta$-caroteno, $\alpha$-caroteno e luteína inferiores apenas aos observados em 'BRS Esplanada' (Tabela 3). No entanto, é interessante observar que 'BRS Esplanada' é uma cultivar de raízes longas que foi desenvolvida para fins de processamento e não para consumo in natura (Vieira et al., 2005). Dessa forma, 'BRS Planalto' poderá ocupar uma posição estratégica na cadeia produtiva de cenoura para consumo in natura, representando uma opção com melhor qualidade visual e nutricional de raízes quando comparada com outras cultivares do grupo varietal Brasília.

\section{Recomendações de plantio}

A cultivar BRS Planalto é recomendada para a semeadura no verão em sistemas de produção convencional e orgânico, nas principais regiões produtoras de cenoura do Brasil, requerendo tratos culturais similares aos adotados para cultivares do grupo varietal Brasília. À semelhança da cultivar Brasília, poderá florescer prematuramente se cultivada na primavera das regiões Centro-Oeste, Sudeste e Sul do Brasil.

\section{Disponibilidade de sementes}

A Embrapa Hortaliças dispõe de sementes genéticas para negociação com os clientes interessados.

\section{Agradecimentos}

Aos funcionários da Embrapa Hortaliças, principalmente à "turma da cenoura".

\section{REFERÊNCIAS}

BOITEUX LS; DELLA VECCHIA PT; REIFSCHNEIDER FJB. 1993. Heritability estimate for resistance to Alternaria dauci in 
carrot. Plant Breeding 110: 165-167.

CEAGESP. 1999. Classificação de cenoura: Programa de adesão voluntária, São Paulo: Programa Horti \& Fruti, 8p. (Folder).

CRUZ CD. 1997. Programa Genes: Aplicativo Computacional em Genética e Estatística. Viçosa: UFV, 442p.

RODRIGUEZ-AMAYA D. 2001. A Guide to Carotenoids Analysis in Food. Washington: International Life Sciences Institute Press, 64p.
THURHAM DI. 2007. Bioequivalence of $\beta$-carotene and retinol. Journal of the Science of Food and Agriculture 87: 13-39.

VIEIRA JV; ARAGÃO FAS; BOITEUX LS. 2003. Heritability and gain from selection for field resistance against multiple root-knot nematode species (Meloidogyne incognita race 1 and $M$. javanica) in carrot. Euphytica 130: 11-16.

VIEIRA JV; SILVA JBC; CHARCHAR
JM; RESENDE FV; FONSECA MEN; CARVALHO AM; MACHADO CMM. 2005. Esplanada: cultivar de cenoura de verão para fins de processamento. Horticultura Brasileira 23: 851-852.

VIEIRA JV; SILVA GO da; BOITEUX LS; SIMON PW. 2009. Divergência genética entre acessos de cenoura pertencentes a grupos varietais distintos utilizando caracteres morfológicos. Horticultura Brasileira 27: 468-472. 